Drs Shiwach and Rutherford (Psychiatric Bulletin, May 1990, 14, 311-312) on this subject.

The construction of sentences using the double negative such as "the Tribunal is not satisfied that the patient is not now suffering from mental disorder" is a form of litotes, which, according to the second edition of Fowler's Modern English Usage, is the same as or a variety of meiosis. We concede that one purpose of rhetorical litotes is to impress by moderation but in Tribunal reports and indeed in legal reports in general such statements, far from being "strong positives" or colloquiallisms like "He didn't say nothing", are used evasively and deliberately to qualify what one is saying when one cannot really say it positively. Hence, for example, although the Tribunal is not satisfied that the patient is suffering from mental disorder, it is not satisfied that the patient is not suffering from such a disorder.

We concede too that patients themselves may have difficulty in understanding the Tribunal's double negatives but the patients are surrounded by highly intelligent carers who could easily explain these sentences to them.

Karinya

Herschel Prins

1 Home Close Road

Haughton-on-the-Hill

Leicestershire LE7 9GB

Fulford Grange Hospital

Micklefield Lane

Rawdon, Leeds LS196BA

\section{General management}

DEAR SIRS

I read with some apprehension and disquiet the letter from Elaine Murphy (Psychiatric Bulletin, April $1990,14,237)$, regarding general management.

I feel that she continues to miss the inherent difficulty in general management in stating that while the service is provided by a team it should be managed by one person, this person being accountable to one other. She, therefore, infers that the team as a whole have faith and confidence in this one person, which, in my own experience, is often not the case and while stating that she found it perfectly acceptable to be accountable to a non-doctor, she did not state in which areas she wishes to be accountable. I note that she, herself, has taken the route of becoming a District General Manager, thus no doubt seeing herself as "managing" her colleagues. However desirable this may be to the smooth running of the multidisciplinary team, in many parts of the country District and Unit General Managers have no medical training and this leads to obvious conflict within the multidisciplinary team.
I firmly believe that psychiatrists remain in the "business" of managing the care of their patients, many of whom are the most vulnerable in society. Conflict caused within teams by lack of confidence and belief in the one person, whom Dr Murphy would hold accountable, only damages the level of care to the patients whom we should serve. Unlike Dr Murphy, I believe that members in the Health Service are right to regard the onset of general management with a healthy cynicism and suspicion. The threat to the co-ordinated wide-ranging care which we currently provide posed by recent Government legislation is only enhanced by such zealot-like views as those expressed by Dr Murphy. General management does have a lot to offer in terms of constant review of our aims and objectives but should not be regarded as an ideal and totally desirable option to other current management structures.

Alastair N. Palin

\section{Mental Health Services Unit}

The Ross Clinic, Cornhill Road

Aberdeen AB9 2ZF

\section{Dear Sirs}

Dr Palin is quite right that a manager who is unable to inspire the confidence of the team members who are accountable to him or her is useless. It is crucial that whether a manager is a clinician or administrator that people are able to respect his/her skills. I also agree with him that there are plenty of bad managers and I should add there are as many bad nurse and doctor managers as there are bad administrator managers. But the fact of the existence of bad managers does not undermine the fundamental importance of having individuals accountable for achieving the overall objectives of a team. Conflicts between professionals will arise in any healthy team and there needs to be an effective means of resolving them. Separate professional lines of management for individuals in a team militate against effective decision making.

Management obviously means very different things to Dr Palin when referring to the activities of a District General Manager (para. 2) compared with what he does when he "manages" the care of patients (para. 3) i.e. work with a team of committed professionals to ensure the best decisions for care and treatment are made within the constraints of the staff and services available to him and the wishes and compliance of the patient. Maybe the same skills are used in both District and patient types of management, when practised effectively.

I may be a zealot for good management but much more of one for good coordinated multidisciplinary care. The two are entirely compatible.

(Until recently District General Manager of ELAINE MURPHY Lewisham and North Southwark Health Authority) Guy's Hospital, London Bridge SE1 9RT 